\title{
Serial Transmission of Plant Viruses by Cutting Implements during Grafting
}

\author{
Michael G. Bausher ${ }^{1}$ \\ USDA-ARS U.S. Horticultural Research Laboratory, 2001 South Rock Road, \\ Fort Pierce, FL 34945
}

Additional index words. meristem, axillary buds, plant pathogens, vegetable production

\begin{abstract}
Reciprocal grafts of two tomato (Solanum lycopersicum L.) cultivars were made by hand using commercial grafting techniques. The razor blade used to cut the rootstock or scion was first contaminated by making a single cut on tomato plants infected with either Tomato spotted wilt virus (TSWV) or Tomato mosaic virus (ToMV). Although no transmission of TSWV was observed in these experiments, ToMV was spread plant to plant through razor blade exposure to this virus. The presence of this virus was confirmed by double-antibody sandwich enzyme-linked immunosorbent assay (DASELISA) at 21 days post-inoculation. The highest rate of infection was $25 \%$ of the inoculated plants. The greatest number of positive virus assays was found in the first $\mathbf{1 0}$ plants of each experiment. These areas contained $84 \%$ of the DAS-ELISA-positive plants. Gaps of up to 10 plants occurred during serial inoculation before infection resumed. Random dispersion occurred in two experiments. Similar results were observed whether the contaminated implement was used to cut the rootstock or the scion before graft assembly. This work demonstrates that some viruses from a single contamination can be moved in a serial manner during the grafting process, especially with varieties with minimal or no resistance to viral plant pathogens. Also, visual diagnosis cannot always be relied on as a means of eliminating virus-infected plants, especially when higher greenhouse and annealing temperatures are maintained.
\end{abstract}

Grafting vegetable plants can improve plant health and yields (Rivard and Louws, 2008). Although grafting improves the resistance of plants to various soilborne diseases, vegetable grafting has its challenges. Cutting devices used to sever stems can provide an ideal mode of transmission of disease inoculum of viral origin. Although all plants can be subject to infection by mechanical transmission of viruses (Boyle et al., 1997), crops such as heirloom tomatoes are especially prone to infection because they do not have virus resistance. Another important factor contributing to disease is the increased use of grafting in combination with high tunnels, greenhouses, or open-field production, creating the ideal situation for transmission of viral disease as a result of tool contamination and mechanical and human activity (Cohen et al., 1999; Lewandowski et al., 2010).

Although transmission of TSWV, a tospovirus, by plant extracts has been reported (Betti, 1992; Zitter, 2006), the most recognized

\footnotetext{
Received for publication 11 June 2012. Accepted for publication 17 Aug. 2012.

Partial funding provided by USDA NIFA Grant 2011-51181-30963.

I thank Scott Adkins for his advice and assistance with the virus assays and Joseph Albano, USDA, ARS, and Pete Stoffella, University of Florida, for organizational reviews of the manuscript. I also thank Andrew Bantel, Carrie Vanderspool, and Lynn Faulkner for their technical assistance during this work and the funding agency USDA-ARS

This work is associated with USDA-ARS Research Project 6618-13000-035-00D.

${ }^{1}$ To whom reprint requests should be addressed; e-mail michael.bausher@ars.usda.gov.
}

source of transmission is thrips (Kumar et al., 1993). On the other hand, the tobamoviruses including ToMV can be transmitted mechanically through contact with soil, water, or foliage (Antignus et al., 1990; Hollings, 1976; Hollings et al., 1975). Both of these diseases are economically important in the United States and worldwide. In addition, reports of viral diseases as a result of the use of viruscontaminated rootstocks have been reported in melons (Choi, 2001). Tobamoviruses are easily moved by human intervention and once introduced can easily result in further plantto-plant dissemination (Choi, 2001). In some cases, this can lead to epidemic levels when virus-contaminated rootstocks are used (Chen et al., 2006). Tomato is especially vulnerable to virus movement as a result of the number of manual operations that must be performed such as grafting and pruning, which are effective methods of virus dissemination. Therefore, the objectives of the research were to determine: 1) the efficiency of a single cut of a virusinfected tomato plant stem to move the virus during grafting; 2) the effect of an infected scion or the rootstock on virus transmission in a grafting system; and 3) if visual diagnosis can be used as a method of eliminating virusinfected plants.

\section{Materials and Methods}

Growing conditions. Tomato varieties 'Rutgers' (scion) and 'Roma' (rootstock) (Sieger Seed, Holland, MI) were grown in 128- (inverted pyramid) cell Speedling (Sun City, FL) trays in ProMix 4P (Premier Horticulture, Quakertown, PA) media in Fort Pierce, FL (lat. $27.41^{\circ} \mathrm{N}$, long. $80.35^{\circ} \mathrm{W}$ ). All plants were fertilized with $20 \mathrm{~N}-10 \mathrm{P}-20 \mathrm{~K}$ fertilizer (Peters Professional; Scotts Company, Marysville, $\mathrm{OH}$ ) at $150 \mathrm{ppm}$ nitrogen weekly beginning 2 weeks after germination. Greenhouse air temperatures were between 30.1 and $36.4{ }^{\circ} \mathrm{C}$ maximum with $60 \%$ to $80 \%$ relative humidity during the experimental period. Four weeks after germination, plants were grafted using silicon clips (Bato, The Netherlands) to secure the union. Graft cuts were made by a new single-edge razor blade (American Safety Razor, Verona, VA), which was exposed to viral inoculum by a single cut into the infected donor plants.

Inoculation source (donor plants). Donor tomato plants were mechanically inoculated with leaf extracts of ToMV (Kamenova et al., 2006) or TSWV from a local Florida source (Atkins and Rosskopf, 2002). Briefly, in both cases, the donor tomato plants were inoculated by sap expressed by a chilled mortar and pestle with $20 \mathrm{~mm}$ sodium sulfite and Celite from fresh tissue sources. Cheesecloths dipped in these preparations were used to abrade the plant leaves during inoculation. All donor plants were assayed for the presence of TSWV or ToMV before conducting grafting tests at $21 \mathrm{~d}$. The mock inoculation source was produced in the same manner from non-infected source plants.

Inoculation protocol. Inoculation of TSWV or ToMV was accomplished by severing the stem of a young donor plant near the terminal region to presumably contaminate the blade with virus and then immediately using the blade to cut the experimental plants used for grafting. Three inoculation treatments were used for each virus. In the first treatment of inoculation, the contaminated blade was used to cut each of 32 rootstock plants in succession and then the scion plants were cut with a new clean blade. The control mock-inoculated scions were cut in the same manner as rootstocks but using a new blade and control virus-free mock inoculated source. In the second treatment set of inoculation, the scion plants were cut with a contaminated blade and the rootstocks were cut with a new clean blade. A third treatment of inoculation (control) was prepared by cutting both scion and rootstock plants with a mock-inoculated razor blade. The graft angle was $\approx 45^{\circ}$ and in each set, the rootstock was severed below the cotyledon. The grafts were then assembled and placed in a growth chamber set at $29{ }^{\circ} \mathrm{C}, 95 \%$ humidity, and light levels of $\approx 100 \mu \mathrm{mol} \cdot \mathrm{m}^{-2} \cdot \mathrm{s}^{-1}$ photosynthetic active radiation $(P A R)$ for $10 \mathrm{~d}$ of a $12-\mathrm{h}$ photoperiod. Treatments (virus-inoculated and mock) were repeated as separate experiments composed of 32 plants for each virus source. Studies were repeated three times for each virus source. After the initial incubation period in the growth chamber, plants were then moved back to the greenhouse and held for $20 \mathrm{~d}$ before assaying for viral infection. Plants were tested using a DAS-ELISA using commercially available ToMV and TSWV antiserum (Agdia, Inc., Elkhart, ID). Briefly, plants were sampled below and above the graft union. In the case of the rootstock, a stem sample of $0.3 \mathrm{~g}$ was taken $0.5 \mathrm{~cm}$ below the graft union. For scions, 
recently matured fully expanded leaves were sampled (0.3 g tissue) for analysis. Sample preparation and processing followed commercial protocol for DAS- ELISA for both TSWV and ToMV. Positive readings were considered $2 \times$ the healthy control baseline at $405 \mathrm{~nm}$ (Sutula et al., 1986).

Statistical analysis. Statistical analysis consisted of a rank sum test of disease incidence using the Mann-Whitney rank-sums test using Systat 3.5 (Systat Software, San Jose, CA). Analysis for randomness was performed using the ordinary runs test to analyze the pattern of occurrence of virus-positive or -negative plants in order of grafting sequence. The graft data were divided into runs that are based on the occurrence of virus positive (assigned " 1 ") or negative (assigned "0") plants. An example of this method and its use can be found in a previous study (Biggs et al., 2008). A sequence run of 1-0-1-00-11 would have five runs. The total of the runs is compared with the expected number of outcomes and from a $P$ value for testing the null hypothesis for randomness. It is the only test of this type based on an ordered sequence (Biggs et al., 2008; Gibbons, 1985). Ordinary runs test was performed using Minitab 15 (State College, PA).

\section{Results and Discussion}

A razor blade exposed to ToMV inoculum resulted in multiple plants with infections resulting from serial grafting. This was true whether the inoculum was delivered through the rootstock or the scion during the grafting process. There were no positive virus assays for any of the six mock-inoculated controls. Significant viral infection $(P<0.002)$ occurred in all instances of the study for the rootstock-inoculated treatment with plants out to the 14th grafted plant with both scion and rootstock testing positive (Table 1). In another case of a rootstock-inoculated treatment, positive tests were found up to the 28th plant, but in this case, the scion was the only part of the plant that was positive. One scioninoculated group (scion-inoculated replication 1) tested positive for both the scion and rootstock out to the 16th plant. Overall there was no statistical difference for infection rates $(P>0.05)$ between the rootstock- and scion-inoculated groups.

Table 1. Double-antibody sandwich enzyme-linked immunosorbent assay result of serial grafting using a razor blade that was previously used to cut a ToMV-infected plant showing infection or not. ${ }^{\mathrm{z}}$

\begin{tabular}{|c|c|c|c|c|c|c|}
\hline \multirow[b]{3}{*}{ Plant no. ${ }^{\mathrm{y}}$} & \multicolumn{3}{|c|}{ Rootstock inoculation (replication) } & \multicolumn{3}{|c|}{ Scion inoculation (replication) } \\
\hline & 1 & 2 & 3 & 1 & 2 & 3 \\
\hline & $\overline{\mathrm{Sci} / \mathrm{RS}^{\mathrm{x}}}$ & Sci/RS & $\overline{\mathrm{Sci} / \mathrm{RS}}$ & $\overline{\mathrm{Sci} / \mathrm{RS}^{\mathrm{w}}}$ & Sci/RS & $\overline{\mathrm{Sci} / \mathrm{RS}}$ \\
\hline 1 & $+/+^{v}$ & $-1-$ & $+/+$ & $-1-$ & $+/+$ & $+/+$ \\
\hline 2 & $-1-$ & $-1-$ & $+/+$ & $-1-$ & $+/+$ & $+/+$ \\
\hline 3 & $+1-$ & $+/+$ & $+1-$ & $-1-$ & $+/+$ & $+/+$ \\
\hline 4 & $+/+$ & $-1-$ & $+/+$ & $-1-$ & $+/+$ & $-1-$ \\
\hline 5 & $+/+$ & $-1-$ & $-1-$ & $+/+$ & $-1-$ & $-1-$ \\
\hline 6 & $-1-$ & $-1-$ & $+/+$ & $-1-$ & $+/+$ & $-1-$ \\
\hline 7 & $-1-$ & $-1-$ & $+/+$ & $+/+$ & $+/+$ & $-1-$ \\
\hline 8 & $+/+$ & $-1-$ & $-1-$ & $-1-$ & $-/+$ & $-1-$ \\
\hline 9 & $-1-$ & $+/+$ & $-1-$ & $-1-$ & $-1-$ & $+/+$ \\
\hline 10 & $-1-$ & $+/+$ & $-1-$ & $-1-$ & $-1-$ & $+/+$ \\
\hline 11 & $-1-$ & $-1-$ & $-1-$ & $-1-$ & $-1-$ & $-1-$ \\
\hline 12 & $-1-$ & $-1-$ & $-1-$ & $-1-$ & $-1-$ & $-1-$ \\
\hline 13 & $-1-$ & $+/+$ & $-1-$ & $-1-$ & $-1-$ & $-1-$ \\
\hline 14 & $-1-$ & $-1-$ & $-1-$ & $+/+$ & $-1-$ & $+/+$ \\
\hline 15 & $-1-$ & $-1-$ & $-1-$ & $-1-$ & $-1-$ & $-1-$ \\
\hline 16 & $-1-$ & $-1-$ & $-1-$ & $+/+$ & $-1-$ & $-1-$ \\
\hline 17 & $-1-$ & $-1-$ & $-/+$ & $+/-$ & $-1-$ & $-1-$ \\
\hline 18 & $-1-$ & $-1-$ & $-1-$ & $-1+$ & $-1-$ & $-1-$ \\
\hline 19 & $-1-$ & $-1-$ & $-1-$ & $-1-$ & $-1-$ & $-1-$ \\
\hline 20 & $-1-$ & $-1-$ & $-1-$ & $-1-$ & $-1-$ & $-1-$ \\
\hline 21 & $-1-$ & $-1-$ & $-1-$ & $-1-$ & $-1-$ & $-1-$ \\
\hline 22 & $-1-$ & $-1-$ & $-1-$ & $-1-$ & $-1-$ & $-1-$ \\
\hline 23 & $-1-$ & $-1-$ & $-1-$ & $-1-$ & $-1-$ & $-1-$ \\
\hline 24 & $-1-$ & $-1-$ & $-1-$ & $-1-$ & $-1-$ & $-1-$ \\
\hline 25 & $-1-$ & $-1-$ & $-1-$ & $-1-$ & $-1-$ & $-1-$ \\
\hline 26 & $-1-$ & $-1-$ & $-1-$ & $-1-$ & $-1-$ & $-1-$ \\
\hline 27 & $-1-$ & $-1-$ & $-1-$ & $-1-$ & $-1-$ & $-1-$ \\
\hline 28 & $-1-$ & $-1-$ & $+/-$ & $-1-$ & $-1-$ & $-1-$ \\
\hline 29 & $-1-$ & $-1-$ & $-1-$ & $-1-$ & $-1-$ & $-1-$ \\
\hline 30 & $-1-$ & $-1-$ & $-1-$ & $-1-$ & $-1-$ & $-1-$ \\
\hline 31 & $-1-$ & $-1-$ & $-1-$ & $-1-$ & $-1-$ & $-1-$ \\
\hline 32 & $-1-$ & $-1-$ & $-1-$ & $-1-$ & $-1-$ & $-1-$ \\
\hline
\end{tabular}

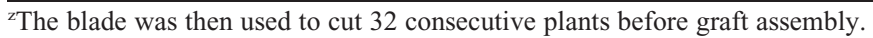

${ }^{y}$ Series of plants cut once by a razor blade.

${ }^{x}$ Rootstock inoculated with a contaminated razor blade.

wScion inoculated with a contaminated razor blade.

${ }^{\mathrm{v} S}$ Scion/rootstock $-=$ negative, $+=$ positive for virus by double-antibody sandwich enzyme-linked immunosorbent assay; all symbols with bold + are positive for ToMV.

ToMV = Tomato mosaic virus.
Infection rates were $15 \%, 13 \%$, and $25 \%$ for the three experiments with rootstockinoculated experiments (replications 1, 2,3), respectively, and $19 \%, 22 \%$, and $19 \%$ for the three scion inoculations (replications 1, 2, 3), respectively (Table 1). The progression of inoculation showed that the inoculum load was spent on the earlier cuts of the blade but still persisted enough to infect plants near the end of the serial grafting run. This is probably the result of: 1) the changing position of the inoculum load as the cutting device is drawn through the stem tissue; 2) friction of the blade against the stem tissue; 3 ) movement of the virus particles in the sap solution; or 4) a combination of these factors. The passing of the blade through each plant during the inoculation process may mimic a dilution end point as the inoculum is reduced by each pass. When ordinary runs analysis was used, the low $P$ value $\leq 0.016$ did not support the null hypothesis for random occurrence of ToMVpositive plants (Table 2) because it did not exceed the threshold probability value needed. Examining the data confirms that a clustering of the virus-positive plants occurred in the first 10 plants of replications $1,3,5$, and 6 . However, in the case of replications 2 and 4, the $P$ values $\geq 0.290$ supported the case for random occurrence of virus-infected plants. It is not clear from the analysis what events caused these random results. It is possible that the dilution of the virus load on the cutting blade may tend to reduce efficient transfer. The movement from the initial infected cells could be impeded by slow integration into the vascular system, which prevented virus movement (Matthews, 1991). This could be the case in those individual inoculations in which the donor plants failed to infect their respective rootstock or scion plants. They did, however, infect the non-inoculated tissue in some cases (see replication 3 plant 3 of rootstock inoculation in Table 1). The DASELISA positive plants were symptomless at the time of assay making visual inspection of plants with virus infection impossible. Infected plants were symptomless probably as a result of the high temperatures in the incubation chamber and greenhouse and interaction of the plant genotype (Averre and

Table 2. Ordinary runs analysis of individual inoculation experiments.

\begin{tabular}{lccrc}
\hline Runs & Treatment $^{\mathrm{z}}$ & ORO $^{\mathrm{y}}$ & ORE $^{\mathrm{x}}$ & $P^{\mathrm{w}}$ \\
\hline 1 & RS inoc & 6 & 9.44 & 0.016 \\
2 & RS inoc & 7 & 8.00 & 0.390 \\
3 & RS inoc & 8 & 13.00 & 0.015 \\
4 & Sci inoc & 9 & 10.75 & 0.291 \\
5 & Sci inoc & 4 & 11.94 & 0.000 \\
6 & Sci inoc & 6 & 10.75 & 0.004 \\
\hline
\end{tabular}

${ }^{\mathrm{z}}$ Inoculation treatments; $\mathrm{RS}=$ rootstock; $\mathrm{Sci}=$ scion; inoc $=$ virus inoculation by razor cut during grafting of either scion or rootstock.

${ }^{y}$ Ordinary runs observed values.

${ }^{\mathrm{x}}$ Ordinary runs expected values.

${ }^{\text {w}}$ Resulting $P$ value derived from the normal standard $z$ is based on an alpha level of 0.05 . Values of $P \leq 0.016$ shown in the table are sufficient evidence to conclude that the null hypothesis of randomness is not supported. 
Gooding, 2000; Hollings, 1976). After the initial annealing and a short hardening period of $3 \mathrm{~d}$, grafted plants are normally planted in the field or greenhouse. Temperatures in the early fall and spring in Florida of greater than $30{ }^{\circ} \mathrm{C}$ are not uncommon. Relative to TSWV, ToMV is a very persistent plant pathogen because both rootstock and scion seeds can be a source of infection. Serial movement of tobamoviruses by grafting has been reported in other grafted plants crop, namely melons. However, in that case, the movement occurred post-grafting and the initial infection was associated with bottlegourd (Lagenaria siceraria) rootstock seed infected with $\mathrm{Cu}$ cumber green mosaic virus (Choi, 2001). In that study, virus transmission by seed initiated a disease cycle by secondary movement of the disease by human activity such as physical movement through the field. Grafting of contaminated plants was found to be a critical element in an epidemic of the same disease in China (Kamenova et al., 2006). The current trend to use varieties that have minimal or no resistance to ToMV such as "heirloom" tomatoes make them especially susceptible to ToMV decline when infected resistant rootstocks are used (Pilowsky, 1971).

It should be noted that a razor blade exposed to TSWV inoculum failed to mechanically transmit the virus during the grafting process. There is reference to mechanical inoculation of TSWV in the literature. In these references, the plant cell contents are expressed from tissue of infected sources and the inoculum is usually obtained by mixing plant sap in buffered preparations with carborundum and hand rubbing the leaves. The inoculation method used in this study did not support mechanical transmission by contaminated blades (Kumar et al., 1993). Some buffering of the plant sap is necessary for infection resulting from the instability of the virus in vitro and therefore the material deposited on the blade lost infectivity (Zitter, 2006).

In conclusion, this study demonstrated the possibility that manual or mechanized cutting equipment used to graft solanaceous plants like tomato can result in the movement of viruses. Also, a single cut can produce up to 21 sequential infected plants, which can be a serious problem in grafted plant production. Also shown here is that the use of contaminated grafting blades has little chance of transmitting TSWV when done under the condition of a single cut of a contaminated plant.

\section{Literature Cited}

Antignus, Y.P., M. Ben Joseph, and M. Cohen. 1990. Occurrence of variant of cucumber green mottle mosaic virus in Israel. Phytoparasitica 18:50-56.

Atkins, S. and E.N. Rosskopf. 2002. Key West nightshade, a new experimental host for plant viruses. Plant Dis. 86:1310-1314.

Averre, C.W. and G.V. Gooding. 2000. Virus diseases of greenhouse tomato and their management. 9 Sept. 2011. <http://www.ces.ncsu. edu/depts/pp/notes/oldnotes/vg15.htm>.

Betti, L. 1992. Tomato spotted wilt virus on eggplant in Sicily [in Italian]. Phytopath. Medit. 119-120.

Biggs, A.R., W.W. Turchek, and T.R. Gottwald. 2008. Analysis of fire blight shoot infection epidemics on apple. Plant Dis. 92:1349-1356.

Boyle, T.H., D.E. Mayhew, and A.L. Wiens. 1997 Viruses in cactus grafting stocks. Cactus and Succulent Journal. 69:40-41.

Chen, H.Y.Z., W.J. Zhao, Y. Cheng, M.F. Li, and S.F. Zhu. 2006. Molecular identification of the virus causing watermelon mosaic disease in MidLiaoning. Acta. Phtopathol. Sin. 4:306-309.

Choi, G.S. 2001. Occurrence of two tobamaovirus diseases in cucurbits and control measures in Korea. Plant Pathol. J. 17:243-248.

Cohen, J., N. Sikron, S. Shuval, and A. Gera. 1999. Susceptibility of vegetatively propagated petunia to tobamovirus infection and its possible control. HortScience 34:292-293.

Gibbons, J.D. 1985. Nonparametric methods for quantitative analysis. American Sciences Press, Columbus, $\mathrm{OH}$

Hollings, M.H. 1976. Tomato mosaic virus. C.M.I./ A.A.B. Descriptions of plant viruses. 156

Hollings, M.K., Y. Komuo, and H. Tochihara. 1975. Cucumber green mottle mosaic virus. Vol. 154. CMI/AAB, Kew, UK

Kamenova, I., S. Adkins, and D. Achor. 2006 Identification of Tomato mosaic virus infection in jasmine. Acta Hort. 722:277-283.

Kumar, N.K.K., D.E. Ullman, and J.J. Cho. 1993. Evaluation of Lycopersicon germ plasm for tomato spotted wilt tospovirus resistance by mechanical and thrips transmission. Plant Dis. 77:938-941.

Lewandowski, D.J., A.J. Hayes, and S. Adkins. 2010. Surprising results from a search for effective disinfectants for Tobacco mosaic viruscontaminated tools. Plant Dis. 94:542-550.

Matthews, R.E.F. 1991. Plant virology. 3rd Ed. Academic Press, San Diego, CA.

Pilowsky, M. 1971. Grafting studies with TM-2 stock. Tomato Genetics Coop Report. 21:36.

Rivard, C.L. and F.J. Louws. 2008. Grafting to manage soilborne diseases in heirloom tomato production. HortScience 43:2014-2111.

Sutula, C.L., J.M. Gillet, S.M. Morrissey, and D.C. Ramsdell. 1986. Interpreting ELISA data and establishing the positive-negative threshold. Plant Dis. 70:722-726.

Zitter, T.A. 2006. Tomato spotted wilt, p. 40. In: Jones, J.B.S., R.E. Zitter, and T.A. (eds.). Compendium of tomato diseases. APS Press, St. Paul, MN. 